\title{
Anaemia in chronic kidney disease in children
}

\section{Inoka Perera}

Senior Registrar in Paediatrics, Nephrology Paediatric Intensive Care Unit, Lady Ridgeway Hospital, Colombo

Anaemia is a common, recognized complication of chronic kidney disease (CKD) among children and adults. It was previously considered as a late complication of CKD occurring when the glomerular filtration rate (GFR) falls below $35 \mathrm{ml}$ $/ \mathrm{min} / 1.73 \mathrm{~m}^{2}$. However, more recent data indicate that the haemoglobin level starts to decline at much lesser degrees of renal impairment, and on average is significantly reduced at GFR below $60 \mathrm{ml} / \mathrm{min} / 1.73 \mathrm{~m}^{2}$ and the severity increases progressively as the renal function deteriorates [1].

The prevalence of cardiovascular disease (CVD) in individuals with progressive kidney disease has been shown to be high in several cross sectional studies. Anaemia and hypertension have been shown to be the principal risk factors for the prevalence of left ventricular hypertrophy in CKD [2]. Although treatment of hypertension early in the course of CKD is widely accepted in clinical practice, treatment of anaemia early has not gained equal priority.
Because of their young age at onset of CKD, children have a high lifetime exposure to these risk factors for CVD. Therefore, it is important to treat modifiable factors that contribute to cardiovascular disease in children.

\section{Definition}

Anaemia is defined in terms of the haemoglobin (Hb) concentration or haematocrit (Hct). The mean normal values of $\mathrm{Hb}$ and $\mathrm{Hct}$ for the healthy is given in Table 1.

A work up for anaemia in patients with CKD should be initiated when the,

- $\mathrm{Hb}<11 \mathrm{~g} / \mathrm{dL} \quad($ Hct $<33 \%)$ in premenopausal females and pre-pubertal patients

- $\mathrm{Hg}<12 \mathrm{~g} / \mathrm{dL}($ Hct 37\%) in adult males and post-menopausal females [3].

Table 1 - Mean normal values of haemoglobin and haematocrit for the healthy, normal population [3]

\begin{tabular}{|l|l|l|}
\hline Age / Gender & $\begin{array}{c}\text { Haemoglobin } \\
(\mathbf{g} / \mathbf{d L}),\end{array}$ & Haematocrit (\%) \\
\hline Birth & $16.5+3.0$ & $51+9$ \\
\hline 1 month & $14.02+4.0$ & $43+6$ \\
\hline 2 to 6 months & $11.5+2.5$ & $35+7$ \\
\hline 6 months to 2 years & $12.0+1.5$ & $36+3$ \\
\hline 2 to 6 years & $12.5+1.0$ & $37+3$ \\
\hline 6 to 12 years & $13.5+2.0$, & $40+5$ \\
\hline 12 to 18 years (male) & $14.5+1.5$, & $43+6$ \\
\hline Menstruating female & $14.0+2.0$ & $41+5$ \\
\hline Adult male/post-menopausal female & $15.5+2.0$ & $47+6$ \\
\hline
\end{tabular}




\section{Causes}

The pathogenesis of anaemia in CKD is multifactorial.

1. Decreased production of erythropoietin (EPO) by the diseased kidney is the primary cause.

2. Bone marrow suppression by uraemic toxins and hyperparathyroidism.

3. Deficiency of iron, folate and vitamin $B_{12}$

4. Reduced red blood cell survival.

5. Blood loss due to - Frequent blood sampling, gastrointestinal bleeding and haemodialysis.

6. Drugs - ACE inhibitors, angiotensin receptor blockers, theophylline

7. Chronic infection or inflammation.

8. Aluminium excess.

9. Underlying haematological disorders.

\section{Complications}

When untreated, anaemia reduces $\mathrm{O}_{2}$ delivery to tissues resulting in a number of physiological adaptations such as modulation of the affinity of $\mathrm{Hb}$ for $\mathrm{O}_{2}$, increase in cardiac output and redistribution of blood flow from the skin to other organs. Increased cardiac output leads to cardiac enlargement, left ventricular hypertrophy and ventricular dysfunction.
Reduced cognition, impaired mental acuity, growth failure, accelerated annual decline in GFR in adolescents, and impaired immune response are other complications known to occur in these patients [4].

\section{Clinical manifestations}

The symptoms and signs of anaemia in patients with CKD are non-specific and may be difficult to distinguish from those due to uraemia. These include loss of appetite, feeding problems, reduced exercise capacity and breathlessness on exertion or at rest, palpitations, and menstrual irregularities among adolescent girls, impaired growth, poor memory and concentration ability leading to reduced school performance.

\section{Investigations}

Patients with a GFR $<60 \mathrm{ml} / \mathrm{min} / 1.73 \mathrm{~m}^{2}$ should be initially screened for the presence of anaemia by measuring $\mathrm{Hb}$ concentration. If it is $<11 \mathrm{~g} / \mathrm{dL}$ in pre-pubertal children, a workup should be initiated with at least the investigations mentioned in Table-2 to determine whether the anaemia is due to CKD or not [5]. An automated cell counter should be used to determine RBC indices, $\mathrm{Hct}$ and $\mathrm{Hb}$ because the results are more easily standardized. It also has the advantage of providing a total white blood cell count and a platelet count.

Table 2 - Evaluation of anemia should consist of measurement of at least the following [5]

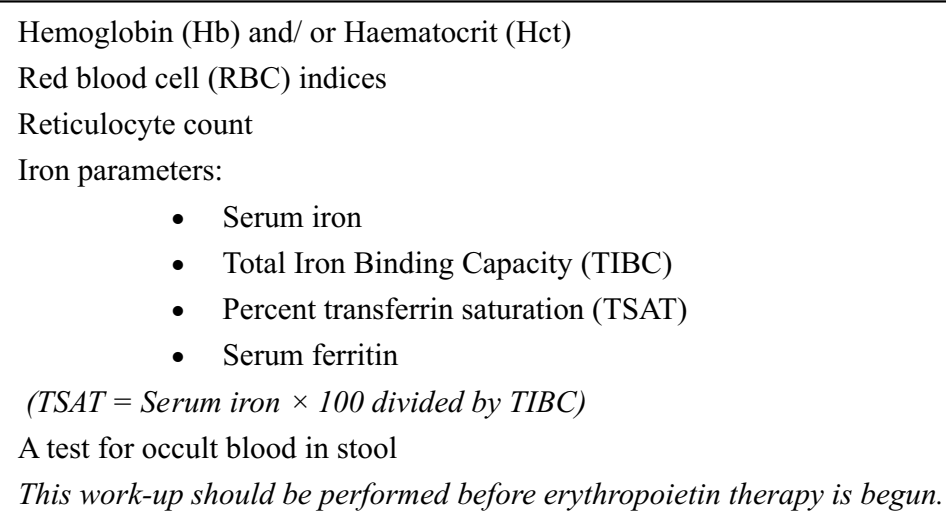


The anaemia of CKD is generally normocytic normochromic. The presence of microcytosis may reflect iron deficiency and aluminium excess whereas macrocytosis may reflect vitamin $B_{12}$ or folate deficiency and/or erythropoietin therapy shifting immature, large reticulocytes into the circulation. Iron deficiency reduces serum iron concentration and lowers TSAT to $<20 \%$. It increases red cell distribution width, TIBC and serum ferritin $(>100 \mathrm{mcg} / \mathrm{L})$ [3].

Serum ferritin is an acute phase reactant and is elevated in infection and/or inflammation. Measurement of C-reactive protein (CRP) level would be helpful to exclude these factors which cause an elevation in the ferritin level.

\section{Management}

The cornerstones of treating anaemic children with CKD include erythropoietin therapy, iron supplementation, treatment of gastritis, suppression of hyperparathyroidism, minimising blood loss during blood sampling and adequate nutrition.

The target range for haemoglobin (haematocrit) should be Hb $11 \mathrm{~g} / \mathrm{dL}$ (33\%) to Hb $12 \mathrm{~g} / \mathrm{dL}$ (36\%) [3]. This target is for erythropoietin therapy and is not an indication for blood transfusion [3].

Iron should be supplemented to prevent iron deficiency and to maintain adequate stores. Iron can be given orally or intravenously (IV). Oral iron should be given at a dose of $2-3 \mathrm{mg} / \mathrm{kg} / \mathrm{day}$ of elemental iron in 2-3 divided doses [3,6]. Oral iron should best be given with food to prevent side effects such as constipation, diarrhoea, nausea and abdominal pain. If compliance is poor due to side effects, the dose can be reduced.

However, oral iron therapy may not be sufficient for correction of anaemia in end stage renal disease. In such patients, parenteral iron is necessary to optimise iron status. Intravenous iron therapy is superior to oral iron supplementation [7]. It can be given safely to CKD patients [8] if international recommendations and guidelines are followed $[3,5]$. Before administering the first dose to a new patient, a test dose of intravenous iron should be given. Potential side effects associated with intravenous iron therapy include acute allergic reactions such as rash, dyspnoea, wheezing or even anaphylaxis, as well as long term complications caused by generation of powerful oxidant species, initiation and propagation of lipid peroxidation, endothelial dysfunction, propagation of vascular smooth muscle proliferation, and/or inhibition of cellular host defence [9]. The preparations available for intravenous administration are iron dextran, iron sucrose and iron gluconate. Iron dextran therapy is associated with a higher risk of allergic reactions than other preparations whereas iron sucrose carries the lowest risk. According to the package insert, iron gluconate has not been established to be safe and effective in paediatric patients [3].

Iron status should be monitored by the TSAT and the serum ferritin [5]. CKD patients should have sufficient iron to achieve and maintain $\mathrm{Hb}$ of 11 to $12 \mathrm{~g} / \mathrm{dL}$ and Hct of $33 \%$ to $36 \%$ [3]. To achieve and maintain this target $\mathrm{Hb}$ and Hct, sufficient iron should be administered to maintain a TSAT of $>20 \%$, and a serum ferritin level of $>100 \mathrm{mcg} / \mathrm{L}$ [3].

If no cause for anaemia other than CKD is detected, and the serum creatinine is $>2.2 \mathrm{mg} / \mathrm{dL}$, anaemia is most likely to be due to erythropoietin deficiency [3]. Erythropoietin treatment has dramatically improved the life of the child with end-stage renal disease. It is beneficial and safe in the pre-dialysis period, during haemodialysis or peritoneal dialysis and after renal transplantation. It is administered subcutaneously (SC) in pre-dialysis, peritoneal dialysis and haemodialysis patients although may be given intravenously (IV) in the latter group to avoid pain. A starting dose of recombinant human erythropoietin ( $r-H u$ EPO) of $50 \mathrm{U} / \mathrm{kg}$ subcutaneously twice weekly is effective and safe for the majority of children with anaemia of chronic renal failure [10]. However, children below 5 years of age have shown to require higher doses ( 300 units $/ \mathrm{kg} / \mathrm{wk}$ ) than older children [3]. Correction of anaemia with r-Hu EPO has not been shown to improve the growth of children with chronic renal failure [11]. 
The side effects of $\mathrm{r}-\mathrm{Hu}$ EPO therapy are hypertension, iron deficiency, hyperkalaemia, arteriovenous fistula, thrombosis, clotting within the extracorporal circuit, thrombocytosis, hyperphosphataemia and headache.

Inadequate response to r-Hu EPO therapy should be evaluated. The commonest cause is iron deficiency. Other causes are infection, inflammation, chronic blood loss, osteitis fibrosa, aluminium toxicity, folate deficiency, vitamin $\mathrm{B}_{12}$ deficiency, malnutrition and haemolysis. An elevated C-reactive protein level indicates the presence of infection or inflammation.

Blood transfusions are best avoided unless absolutely necessary as it may result in alloimmunization of the recipient resulting in graft rejection following kidney transplant. Also, blood transfusions carry the risk of transmission of HIV, Hepatitis B and C infections. Repeated blood transfusions can cause haemosiderosis which may need chelation therapy.

Attention should also be paid to adequate nutrition including folate and vitamin $\mathrm{B}_{12}$ intake and suppression of secondary hyperparathyroidism.

In conclusion, early treatment of anaemia in CKD has shown to reduce cardiovascular disease and blood transfusion requirements with an improvement in exercise tolerance, cognitive functions and quality of life $[12,13]$.

\section{References}

1. WH Kazmi. et al. Anaemia: an early complication of chronic renal insufficiency. American Journal of Kidney Disease. 2001; 38: 8.03-12.

2. RN Foley. Anaemia: Cardiovascular adaptations and maladaptive responses in chronic kidney disease. Nephrology Dialysis Transplantation 2002; 27: 32-4.

3. K/DOQI: National Kidney Foundation (2006). Clinical practice recommendations for anaemia in chronic kidney disease in children. American Journal of Kidney Disease 2006; 47 (3): 86-108.
4. SL Furth. et al .The association of anaemia and hypoalbuminaemia with accelerated decline in GFR among adolescents with chronic kidney disease. Paediatric Nephrology 2007; 22: 265-371.

5. K/DOQI: National Kidney Disease (2006) Clinical practice guideline and clinical practice recommendations for anaemia in chronic kidney disease. American Journal of Kidney Disease 47(3): 11-145.

6. Van Damme-Lombaerts R, J Herman. Erythropoietin treatment in children with renal failure. Paediatric Nephrology 1999; 13: 148-152.

7. Van Wyck DB, M Roppolo, CO Martinez, RM Mazey, MaMurray S: For the United State Iron Sucrose (Venofer) Clinical Trials Group. A randomoized, control trial comparing IV iron sucrose to anaemic patients with non-dialysis dependant CKD. Kidney International 2005; 68:2849-56.

8. CM Chertow, PD Mason, O Vagge-Nilsen, J Ahimen. On the relative safety of parenteral iron formulations. Nephrology Dialysis Transplantation 2004; 19: 15715 .

9. HH Walter. Iron therapy for renal anaemia: how much needed, how much harmful? Paediatric Nephrology 2007; 22: 480-9.

10. JR Burke. Low dose subcutaneous recombinant erythropoietin in children with chronic renal failure. Paediatric Nephrology 1995; 9: 558-61.

11. K Jabs. The effects of recombinant human erythropoietin and nutritional status. Paediatric Nephrology 1996; 10: 324-7.

12. G Ekonyan. The importance of early treatment of anaemia of chronic kidney disease. Nephrology Dialysis Transplantation 2001; 16:45-9.

13. E Baraldi, G Montini, S Zanconoto, G Zachchelo, F Zachchello. Exercise tolerance after a correction with recombinant human erythropoietin in end stage renal disease. Paediatric Nephrology 1990; 4: 623-6. 